\title{
Uncertainty Multi-source Information Fusion for Intelligent Flood Risk Analysis Based on Random Set Theory
}

\author{
Yajuan Xie ${ }^{*}$, Shanzhen Yi, Zhongqian Tang \\ Digital Engineering \& Simulation Research Center, Huazhong University of Science and \\ Technology, No.1037 Luoyu Road, Wuhan 430074, China \\ *Corresponding author E-Mail: phdyjxie@gmail.com
}

\author{
Dengpan Ye \\ Computer School of Wuhan University, Wuhan University,No.129 Luoyu Road, Wuhan 430074, China \\ E-Mail:yedp@whu.edu.cn, \\ http://whu.edu.cn \\ Received 30 November 2011 \\ Accepted 19 June 2012
}

\begin{abstract}
Information fusion has been a hot topic currently, how to make information fusion for intelligent decision is a challenge. Although the applications of random set theory attract many researchers, the probability function distribution is still imprecise. In this paper, we give a new definition of probability distribution function (PDF) of random set theory, and propose an integration methodology for urban flood risk assessment by fusing multi-source information (e. g., remote sensing images, Digital Elevation Model (DEM) and rainstorm data) based on random set theory. The methodology analyzes and fuses the multi-source information, which overcomes the uncertainty of the decision makers of flood risk and generates precise estimates of the probability of flood risk. In our experiments, we take Wuhan city in China and three kinds of data sources information as an example to assess flood risk level. The experiments indicate that our algorithm not only provide precise estimates of the probability of flood risk but also give the bound of probability.
\end{abstract}

Keywords: Information fusion, Multi-source information, Random set theory, Risk analysis.

\section{Introduction}

With the development of modern scientific technology, kinds of information have increased rapidly. On the one hand, people benefit from the abundant information, and on the other hand, people bear the decision trouble because of the poor management of information. How to make the information fusion for the intelligent decision has been a hot topic ${ }^{1,2,3}$. Multi-source information fusion is proposed in $20^{\text {th }}$ century which refers processing the information from different data sources using computer technology. With the rapid development of information technology, multi-source information fusion has great progress. There have been some methods of expression and fusion, for example, Dempster-Shafer (DS) evidence theory has a good description and processing of uncertain information; and fuzzy information is usually processed by a fuzzy set or fuzzy comprehensive evaluation method. In addition, Bayesian theory is also applied to deal with uncertain information modeling.

* Corresponding author 
While the above methods can handle a certain type of information well, but sometimes in practical applications there are different types of data to fuse. In flood risk analysis, it usually needs to conduct different types of information. However, the traditional data fusion theory is lack of strong mathematical basis and an effective comprehensive analysis and judgment. It needs to find a new multi-source information fusion method. In recent years, random set theory has been widely developed by information fusion theory, the Applications of random sets attracted many researchers 4,5 . The theory of random sets was apparently first introduced by Robbins ${ }^{6}$ and utilized by several other investigators ${ }^{7,8,9,10}$; some researchers explore further applications of random set theory to data or information fusion and multi-target tracking ${ }^{11,12}$. Random set theory provides a powerful mathematical tool for fusion problem of multi-source heterogeneous information and also provides a new method for dealing with flood risk analysis.

Flood continues to pose a major challenge in both advanced and developing countries despite significant advances in engineering practice and management approach over the last several decades ${ }^{13}$. Urban flood risk assessment is a complex process due to complexities of rapid urbanization which may cause different change to flood risk factors, which has been a very popular research topic ${ }^{14,15,16,17,18,19}$.

In fact, many researchers consider only one factor in flood risk assessment; for example, Kim et al. use sewer networks to model a prototype of the urban flood warning system ${ }^{20}$. Zhu and Schumann et al. make the urban flood damage estimation using land use deriving from remote sensing image ${ }^{21}$. Wang et al. analyze urban flood risk based on digital terrain model. However, true flood risk is affected by many factors ${ }^{22}$, such as physical, social, economic and political factors, etc. With the development of information technology, it is easy to get multi-source data from different information sources. It makes sense to fuse these factors to assess urban flood risk in an area in the light of actual conditions.

In this paper, a model for assessing urban flood risk based on random set theory can integrate multi-source information and improve the accuracy of flood risk analysis. We take Wuhan city in middle of China as an example to make an integration of multi-source information based on random set theory to assess urban flood risk because Wuhan city is prone to be in flood risk. The factors considered in this paper are the rainstorm precipitation, land use, digital elevation, which can be obtained by different sensors and data sources.

Although many studies have proposed to use random sets for modeling, none have considered the problem of input parameter for large datasets and the imprecise of the function of probability function distribution (PDF) always exists ${ }^{23}$. In this paper we propose a new definition of the PDF of a random set for flood risk, we proposed an integration operator; the results of which will be used as the PDF of random set theory in the urban flood risk analysis, which can reduce the imprecise of PDF.

The paper is organized as follows. In section 2, we give an overview of the basic notions about random sets. Section 3 proposes an integration operator and an information fusion model based on random set theory. In Section 4 we introduce the study area and describe experiment and discussion. Finally, we give a conclusion in section 5 .

\section{Random Set Theory}

Random set theory is an extension of traditional probability theory, which is a mapping from the basic event to a subset of elements in the measurable space. Random set theory attracted wide attention in recent years.

Random sets are sets defined on probability space where values are represented as sets rather than points $24,25,26$. A random set is a multi-valued mapping which is caused by the existence of imprecise information and it can be considered as the imprecise observation of a random variable. It is a generalization of a random variable $^{27}$. The comparison of a random set and a random variable is illustrated in Figure $1^{28}$. Where $\Omega$ is the sample space, $U$ is the universe of discourse denoted as $2^{U}$.

Let $U$ be a universal non-empty set containing all the possible values of a variable $u$. According to ${ }^{29,30}$, a random set on $U$ is defined as a pair $(R, m)$. Where $R=$ $\left\{A_{i}: \mathrm{i}=1 \ldots \mathrm{n}\right\}$ is a finite family of distinct non-empty subsets of $\mathrm{U}$ and $\mathrm{m}$ is a mapping, $R \rightarrow[0,1]$, and $m(\varphi)=0$ and $\sum_{A_{i} \in R} m\left(A_{i}\right)=1$.

Where, $R$ is called the family of the random set and $\mathrm{m}$ is called the PDF, if $m(A)>0$, then the set $A$ is called the focal elements $(A \in R)$, which contains some possible 
values of the variable $\mathrm{u}$, and $m(A)$ can be viewed as the probability that $A$ is the actual range of $u$. According to Dubois and Prade $^{31}$, the value $m(A)$ expresses the proportion to the set $A$ alone, and it does not imply any additional claims regarding subsets of $A$. If there is some additional evidence supporting the claim that the element belongs to a subset $B$ of $A$, it must be explicitly expressed by another value, $m(B)$.

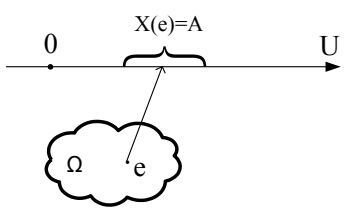

(a)

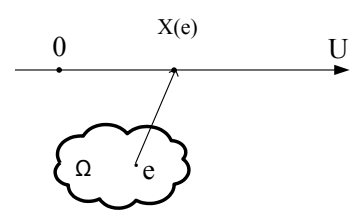

(b)
Figure 1.Comparison between (a) random set and (b) a random variable.

The main difference between a PDF and a basic probability assignment is that the first one is defined on $U^{32}$, whereas the second is defined on the power set of $U$. As a consequence, we obtain the following properties of $m^{33}$ :

- It is required that $m(U)=1$;

- It is not required that $m(A) \leq m(B)$ when $A \subset B$;

- No relationship between $m(A)$ and $m\left(A^{c}\right)$ is required, where $m\left(A^{c}\right)$ is the complementary set of $A$;

- If there are two or more focal elements, then $m(U)$ $<1$.

Because of the imprecise nature of this formulation it is not possible to calculate the precise probability (Pro) of a generic $u \in U$ or of a generic subset $E \subset U$, but only lower and upper bounds on this probability: $\operatorname{Bel}(E)$ $\leq \operatorname{Pro}(E) \leq P l(E)$. Figure 2 shows possible 'precise' probabilities (Pro) bounded by $\mathrm{Pl}(E)$ and $\mathrm{Bel}(E)$. In the limiting case, when $\mathrm{R}$ is only composed of single values (singletons), then $\operatorname{Bel}(E)=\operatorname{Pro}(E)=P l(E)$ and $\mathrm{m}$ is a PDF.

Following Dempster ${ }^{34}$ and Shafer ${ }^{35}$, the lower bound Bel $(E)$ and the upper bound $P l(E)$ of its probability measurement is defined. For every subset $E \subset U$ :

$$
\begin{aligned}
& \operatorname{Bel}(E)=\sum_{A_{i}: A_{i} \subseteq E} m\left(A_{i}\right) \\
& \operatorname{Pl}(E)=\sum_{A_{i}: A_{i} \cap E \neq \phi} m\left(A_{i}\right)
\end{aligned}
$$

Where, the belief function $\mathrm{Bel}(E)$ is a set-valued function obtained through summation of PDF of subsets $A_{i}$ included in $E$, and the plausibility function $P l(E)$ is also a set-valued function obtained through summation of PDF of subsets $A_{i}$ having a non-empty intersection with $E$. Each of them is the right and left envelopes of all possible cumulative distribution functions (CDF) compatible with the data. See the Figure 2.

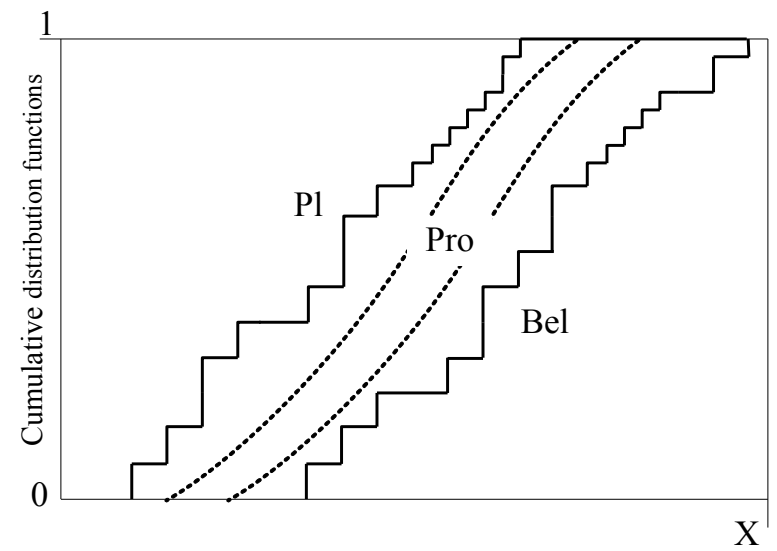

Figure 2.Upper bound (Pl) and lower bound (Bel) on probability (Pro).

Obviously, Bel $(E) \leq P l(E)$. The range of probability of set $E$ denoted as Pro $(E)$ lies between $\mathrm{Bel}(E)$ and $P l$ (E).

$$
\operatorname{Bel}(E) \leq \operatorname{Pro}(E) \leq P l(E)
$$

For simplicity, random sets used in this research refer to finite random sets as there is another type of random set, i.e. random closed set ${ }^{26}$.

\section{Multi-source Information Fusion Based on Random Set Theory}

\subsection{Multi-source Information}

The data related to urban flood risk are diverse which involve hazard-formative environments, hazardformative factors and hazard-affected bodies, etc. Since some factors bear the characteristics of complexity and uncertainty, the influencing factors are incomplete and heterogeneous. In this paper, three kinds of data suitable for the study area are considered: rainstorm data, land use and Digital Elevation Model (DEM) data.

- Rainstorm data is the prerequisite for urban flood risk, which can be obtained from the meteorological observatory and Water Authority sectors.

- Land use data can be obtained by sensor image processing, which is corresponding to the impermeable layer, vegetation land and water area.

- DEM data has different precision with different resolutions of sampling. However, the elevation 
statistics can be got to present the surroundings of one area.

\subsection{Multi-source Information integration operator and input of random set theory}

In this paper, the influencing elements of urban flood risk we considered are rainstorm, land use and DEM data, which are decisive factors in urban flood risk. Each element has a corresponding probability of flood risk according to the histogram statistics. In this paper, we proposed a multi-source information integration operator which is a function of these three factors based on accumulating water volume standard in China city ${ }^{27}$.

$$
\begin{gathered}
Q=q \varphi F \\
P(Q)=P_{1}(q) P_{2}(\varphi) P_{3}(F)
\end{gathered}
$$

Where, $Q$ is surface gathered water volume, $P(Q)$ is the corresponding flood risk probability, $q$ is rainstorm intensity, corresponding to rainstorm data and flood risk probability $P_{1} ; \varphi$ is runoff coefficient, corresponding to the factual terrain and flood risk probability $P_{2} ; F$ is specific catchments area(SCA), corresponding to the land use and flood risk probability $P_{3}$, which can be got from the remote sense image. The probability of urban flood risk is got from the product of probabilities of these three factors. Then the minima and maxima probability of flood risk resulted from water volume can be determined and is presented as the interval [minima, maxima].

\section{- Minima}

A place with the highest terrain, highest vegetation cover rations and minima rainstorm precipitation, we define the product of these three probabilities is the minima probability;

\section{- Maxima}

A place with the lowest terrain, lowest vegetation cover ration and maxima rainstorm precipitation, we define the product of these three probabilities is the maxima probability.

Many studies have proposed to use random sets for modeling the uncertainty of study objects with uncertainty boundaries, but none have considered the problem of input parameter for large datasets. In this paper, the results of multi-source information integration operator will be used as the PDF of random set theory in the urban flood risk

The study area of flood risk is composed of several districts which have different multi-source information, i.e. terrain, land use and precipitation, so the risk probability of different sample sites is different for urban flood risk. In this paper, the risk PDF of focal sets based on random set are between the interval [minima, maxima] shown as above, which improves the accuracy of risk analysis decision.

\subsection{Multi-source Information Fusion Based on Random Set Theory}

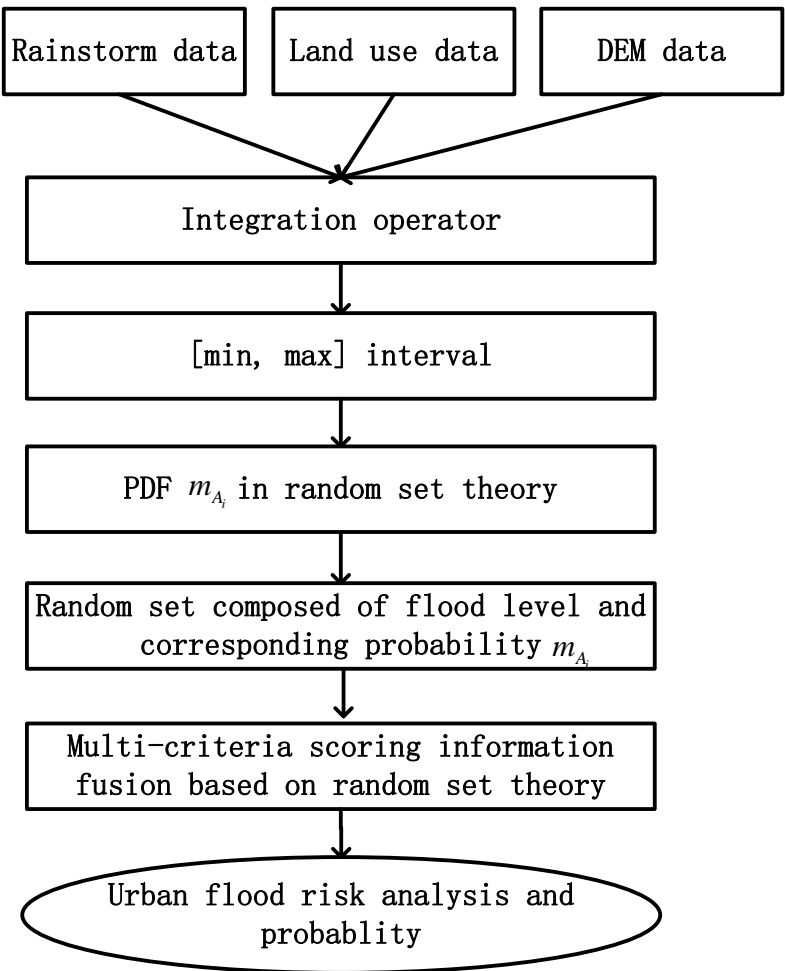

Figure 3.Flow chart in flood risk assessment based on multisource information fusion and random set theory.

In this paper, we make multi-source information fusion to assess flood risk based on random set theory. Firstly, three kinds of multi-source information are collected and analyzed according to the relation with urban flood risk. Secondly, the heterogeneous information is integrated by integration operator introduced in the paper. The integration results are represented as minima and maxima probability of urban flood risk according to accumulating water volume. Thirdly, different probability of each focal set based on multi-source information has been given according to different sampled sites, which are between [minima, maxima]. Then we can get the input of PDF in random set of flood risk level and make the urban flood risk assessment. 
Finally, urban flood risk level and uncertainty probability of urban flood risk in the case study area are obtained. The flow chart is illustrated in Figure 3.

\section{Experiment and Discussion}

\subsection{Study Area}

Wuhan, the provincial capital city of Hubei and the largest central city of Central China region, lies at a latitude of between $29^{\circ} 58^{\prime}$ and $31^{\circ} 22^{\prime}$ north, longitude $113^{\circ} 41^{\prime}$ and $115^{\circ} 05^{\prime}$ east, which is in the middle reaches of the Yangtze River, shown as in Figure 4. In general, the rainy season is from May to October; June is the highest concentrate rainy season. However, it is a region with high urban flood risk. According to the rainstorm frequent statistics from 1880 to 2007 in Wuhan Water Authority, the record of heavy rain $(25 \mathrm{~mm}-49.9 \mathrm{~mm})$ is only one piece, however, the record of rainstorm $(50 \mathrm{~mm}-99.9 \mathrm{~mm})$ is 50 pieces, and heavy rainstorm $(99.9 \mathrm{~mm}-249.9 \mathrm{~mm}) 53$ pieces, extreme heavy rainstorm $(>250 \mathrm{~mm}) 5$ pieces, which shows that urban flood risk in Wuhan city is high according to the record of rainstorm and heavy rainstorm occurrence.

Human activity has changed the characteristics of urban hydrology with the economic development at a high speed. The reduction of lake number and lake area weakened the capability of regulation and catching the rain water. Increase of concrete area also reduced the penetration of the rain water into soil. Furthermore, the old drainage system standard cannot meet the extreme increasing requirement resulted from rapid urbanization such as culvert building according to the old rainstorm flood standard, which will take a long time to improve the drainage condition. In addition, the average elevation of the city is $20-24$ meter, lower than the average flood alarm water level $23.87 \mathrm{~m}$.

Urban flood risk is a limiting factor for the construction and development of Wuhan city. According to historical records, since 1865 , the city has been flooded two times, the most serious is in 1931, most areas of city was flooded except only high land, the water depth is more than $6 \mathrm{~m}^{37}$.

Urban flood may provoke serious effect to normal life and activities, e.g. traffic jams, and houses inundating, etc. The rainstorm from 17th to 19th July, in 2004, from 27th to 28th May, in 2008, and 18th June in 2011 all cause serious urban flood. Therefore, urban flood risk assessment plays an important role in urban planning and sustainable development ${ }^{38,39}$.

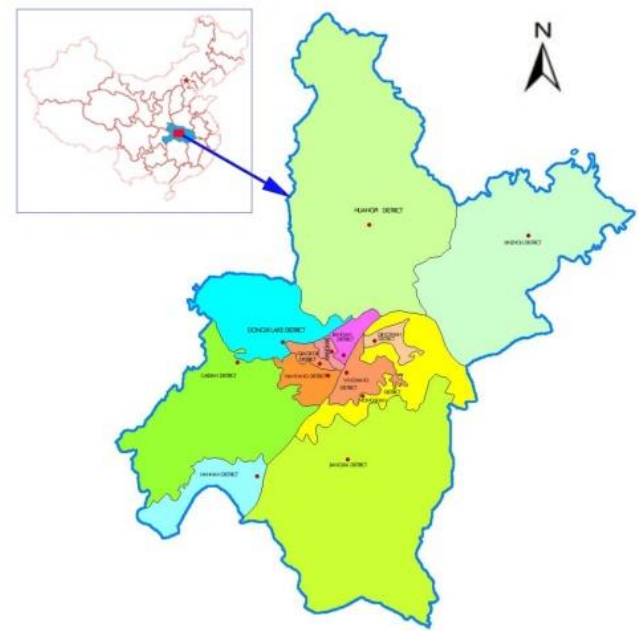

Figure 4.Study area Wuhan in China.

\subsection{Multi-source Information Analysis}

\subsubsection{DEM terrain data}

The Digital Elevation Model (DEM) data in this study is generated from Google Earth geographic coordinate system. The resolution of DEM is $30 \mathrm{~km}$. The highest elevation in the study area is $227.7 \mathrm{~m}$ and the lowest is $13.0 \mathrm{~m}$, the average elevation is $26.9 \mathrm{~m}$. In order to describe the factual terrain in flood, we ignore the values more than or equal to $90 \mathrm{~m}$, which is mountain or high land in the city. ESRI ARCGIS ${ }^{\circledR}$ was used for spatial analysis as shown in Figure 5.

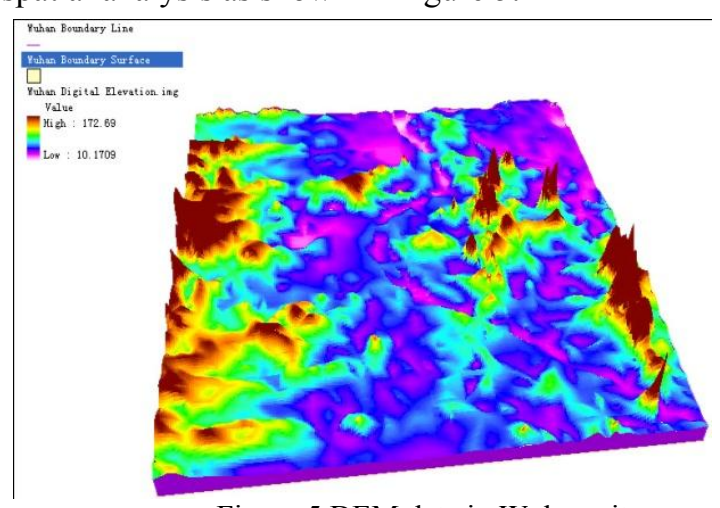

Figure 5.DEM data in Wuhan city.

We divided the elevation into three levels according to the highest elevation, average value and the lowest elevation as shown in Table 1.Where, average is the average value of elevation, corresponding percent is equal to the value of divided total elevation point amount by corresponding elevation point amount. 
Average-2 is the elevation $2 \mathrm{~m}$ lower than average; others are similar to average- 2 . The classification is more factual based on the fact that the design flood level is $34.75 \mathrm{~m}$, the height of levee is $28 \mathrm{~m}$, and the average water level is $23.87 \mathrm{~m}$.

Table 1.Classification of elevation in flood risk.

\begin{tabular}{ccc}
\hline $\begin{array}{c}\text { Urban } \\
\text { flood risk } \\
\text { level }\end{array}$ & Bound of elevation & $\begin{array}{l}\text { Corresponding } \\
\text { percent }\end{array}$ \\
\hline Level 1 & $\begin{array}{c}\text { Average-2 } \\
\text { Highest }\end{array}$ & $29.6 \%$ \\
Level 2 & $\begin{array}{c}\text { Average-8 } ~ \\
\text { Average+2 }\end{array}$ \\
Level 3 & $\begin{array}{c}\text { Lowest } ~ \\
\text { Average-8 }\end{array}$ \\
\hline
\end{tabular}

\subsubsection{Precipitation data}

Wuhan city has frequent rainstorm which is the major factor of urban flood risk. According to the 109 pieces of records between 1880 and 2007 from the statistics of Wuhan Water Authority, only one piece of record is heavy rain, 50 pieces rainstorm, and 53 pieces heavy rainstorm, 5 pieces extremely heavy rainstorm, the rate of rainstorm and heavy rainstorm is $46 \%$ and $49 \%$ respectively. Wuhan city has been often flooded since 1949, the most serious are 1954, 1980, 1983, 1991 and 1998. During the flood in 1983 the highest water level is $28.11 \mathrm{~m}, 4 \mathrm{~m}$ higher than the average elevation, affected area by flood is $62 \mathrm{~km}^{2}$, including 80,000 acres of farm fields and 2620 collapsed buildings, economical loss more than 0.25 billion $\mathrm{RMB}^{40}$.

Precipitation data between $25 \mathrm{~mm}-249.9 \mathrm{~mm}$ from January, 2008 to November, 2011 provided by Wuhan Water Authority auto-detect sensor net was used to derive information on the precipitation distribution, which refresh its precipitation data every 50 seconds. According to the statistics, heavy rain $(25 \mathrm{~mm}-49.9 \mathrm{~mm})$ has 471 records, rainstorm $(50 \mathrm{~mm}-99.9 \mathrm{~mm}) 154$ records, heavy rainstorm (100mm - 249.9mm) 22 records; detailed statistics is shown in Table 2.

The main characteristic of precipitation is long lasting and short interval of time, which makes the soil with high humid condition in Wuhan. Furthermore, rapid urbanization makes the ability of soil permeability lower, which causes urban flood easily and becomes a hamper and danger to the development of Wuhan city. Finally, the drainage is difficult in the area lower than average elevation. In addition, Wuhan city has more than ten millions of residents. Rapidly response to deal with rainstorm and activating emergency plan is important for people's life and the development of Wuhan.

Table 2. Precipitation statistics from January 2008 to November 2011.

\begin{tabular}{lll}
\hline Rainfall & Precipitation & Proportion \\
\hline Heavy rain & $25 \mathrm{~mm}-49.9 \mathrm{~mm}$ & $72.8 \%$ \\
Rainstorm & $50 \mathrm{~mm}-99.9 \mathrm{~mm}$ & $23.8 \%$ \\
Heavy rainstorm & $100 \mathrm{~mm}-$ & $3.4 \%$ \\
& $249.9 \mathrm{~mm}$ & \\
\hline
\end{tabular}

\subsubsection{Land use data}

Remotely sensed image is used for this study, which is a Landsat Thematic Mapper data (TM-5) dated April 28, 2008. The image selected is clear and nearly free of clouds. The image processing and data manipulation were conducted by using algorithms supplied with the ERDAS IMAGE 8.7® image processing software. Table 3. Land use classification.

\begin{tabular}{lll}
\hline Class & Classified points & proportion \\
\hline City land & 757,481 & $33.7 \%$ \\
Vegetation & $1,048,285$ & $46.6 \%$ \\
Water area & 444,234 & $19.7 \%$ \\
\hline
\end{tabular}

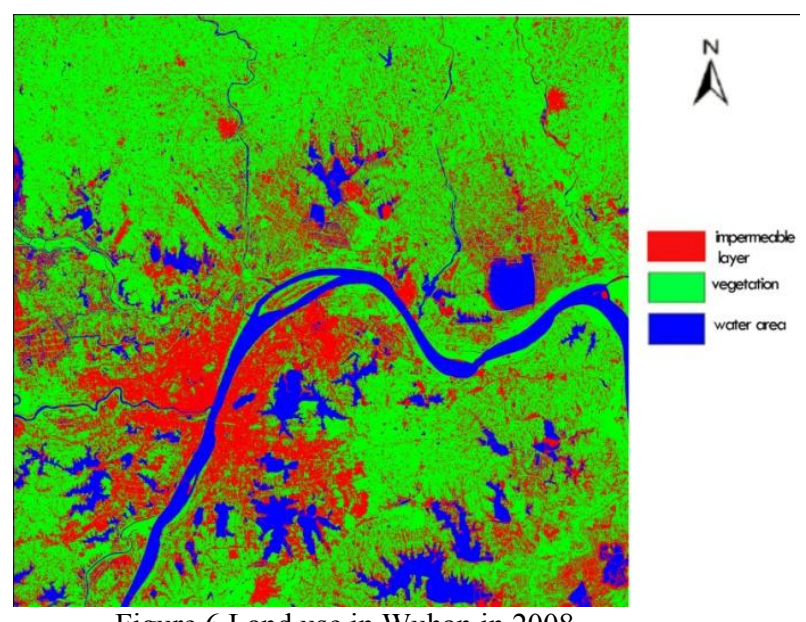

Figure 6.Land use in Wuhan in 2008

Land use and land cover patterns for 2008 were mapped by the use of Landsat TM data. Three categories of land covers were presented in the study area based on their image characteristics and the soil permeability. These covers include impermeable layer, vegetation, and water body. The results are shown in Figure 6, and Table 3. 


\subsection{Case Calculation}

\subsubsection{Random set measure of urban flood risk}

In order to assess the urban flood extent and degree, we divided the flood risk into four levels according to the Wuhan flood data and documents over the years ${ }^{41}$ and classification standard of Wuhan central meteorological observatory ${ }^{42}$. Meanwhile, we divided the water depth of inundated areas into four classes corresponding to flood risk level as shown in Table 4.

In the following, we will make urban flood risk assessment which uses Wuhan city as example. The probabilities of different sample sites for flood risk sets are determined according to the interval [minima, maxima].

Table 4. Water depth classification of flood areas.

urban Flood accumulative Degree of damage

flood water depth $(\omega / \mathrm{m})$

risk

level

\begin{tabular}{lll}
\hline 1 & $0.00<\omega \leq 0.05$ & no urban flood \\
2 & $0.05<\omega \leq 0.30$ & slightly urban flood \\
3 & $0.30<\omega \leq 0.60$ & moderate urban flood, \\
4 & $\omega>0.60$ & Serious flood \\
\hline
\end{tabular}

4.3.2. Bound of flood risk probability in random set theory

- Bound of minima probability

According to the equation (5), minima probability $P(Q)$ is $3.8 \%$, where the highest precipitation $P_{1}(q)$ is $23.8 \%+3.4 \%=27.2 \%$, which includes precipitation more than $50 \mathrm{~mm}$, probability of the lowest terrain $P_{2}(\varphi)$ is $41.0 \%$, and minima vegetation cover ratio $P_{3}(F)$ is $33.7 \%$,

- Bound of maxima probability

According to the equation (5), maxima probability $P(Q)$ is $14.3 \%$, where the minima precipitation $P_{1}(q)$ is $72.8 \%$, probability of highest terrain $P_{2}(\varphi)$ is $29.6 \%$, which includes the elevation $2 \mathrm{~m}$ more than average elevation; The highest vegetation cover ratio $P_{3}(F)$ is $66.3 \%$, which includes vegetation layer and water area.

The probability based on integration operator will be limited in the bound $[3.8 \%, 14.3 \%]$, according to the rule above, different flood risk sets have different probability, shown as in Table 5. Where $A_{i}$ is the flood risk focal element in random set theory, $m\left(A_{i}\right)$ is the corresponding probability of $A_{i}$, Focal element are composed of flood risk levels.

Table 5. Random set measuring urban flood risk.

\begin{tabular}{lll}
\hline$A_{i}$ & Focal element & $m\left(A_{i}\right)$ \\
\hline$A_{1}$ & $(1,2,3)$ & $m\left(A_{1}\right)=12 \%$ \\
$A_{2}$ & $(2,3)$ & $m\left(A_{2}\right)=11 \%$ \\
$A_{3}$ & $(2,3,4)$ & $m\left(A_{3}\right)=12 \%$ \\
$A_{4}$ & $(3,4)$ & $m\left(A_{4}\right)=11 \%$ \\
$A_{5}$ & $(1,2,3,4)$ & $m\left(A_{5}\right)=12 \%$ \\
$A_{6}$ & $(3)$ & $m\left(A_{6}\right)=12 \%$ \\
$A_{7}$ & $(4)$ & $m\left(A_{7}\right)=11 \%$ \\
$A_{8}$ & $(1,2)$ & $m\left(A_{8}\right)=10 \%$ \\
$A_{9}$ & $(2)$ & $m\left(A_{9}\right)=9 \%$ \\
\hline
\end{tabular}

Let us now assess the belief and plausibility function of each value of singletons from level 1 to level 4 , since the maxima in urban flood risk is 4 , for any level $\geq 4$, the belief and plausibility functions vanish. The results of calculation of $\operatorname{Bel}(P)$ and $P l(P)$ are summarized in Table 6 . We observe that the belief of the single values of $\mathrm{P}$ is positive only for $\mathrm{P}=2,3$ and $P=4$, because $\{2\}$, $\{3\}$ and $\{4\}$ are focal elements of the random set. Table 6. Belief and plausibility value of urban flood risk level.

\begin{tabular}{lll}
\hline $\begin{array}{l}\text { Flood } \\
\text { risk } \\
\text { level }\end{array}$ & $\operatorname{Bel}(P)$ & $P l(P)$ \\
\hline 1 & 0 & $m_{1}+m_{5}+m_{8}=34 \%$ \\
2 & $m_{9}=9 \%$ & $m_{1}+m_{2}+m_{3}+m_{5}+m_{8}+m_{9}=66 \%$ \\
3 & $m_{6}=12 \%$ & $m_{1}+m_{2}+m_{3}+m_{4}+m_{5}+m_{6}=70 \%$ \\
4 & $m_{7}=11 \%$ & $m_{3}+m_{4}+m_{5}+m_{7}=46 \%$ \\
\hline
\end{tabular}

\subsubsection{Urban flood risk assessment}

Let us now apply the above information for urban flood risk assessment, when the probability of flood water depth is more than $50 \%$, we consider that the flood level risk exceeds the ability of present drainage and flood defend, the corresponding risk level is urban flood risk level.

In this case, we are interested in checking if the inundation proportion requirement is met. This requirement must satisfy the following inequality: 


$$
\left.P l(E)=P l\left\{P \leq P_{0}\right\}\right) \geq r
$$

Where, $E=\left\{P \leq P_{0}\right\}$ is a set, $P_{0}$ takes on flood risk level, $r$ is set at 0.5 . The belief and plausibility functions of $E$ are given when $P_{0}$ varies shown in Table 7. Figure 7 portrays $\operatorname{Bel}\left(P_{0}\right)$ and $\operatorname{Pl}\left(P_{0}\right)$ as a function of $P_{0}$. Of interest is the set $E=\{P \leq 3\}$, whose bounds of probability are:

$$
\begin{gathered}
\operatorname{Bel}(\{P \leq 3\})=0.54 \\
P l(\{P \leq 3\})=0.89
\end{gathered}
$$

We conclude that the actual urban flood risk level in Wuhan city is level 3, which exceeds the ability of present drainage and flood defense measures and the probability of flood risk 3 is bounded by these two quantities:

$$
\operatorname{Bel}(\{\mathrm{P} \leq 3\}) \leq \mathrm{R} \leq \mathrm{Pl}(\{\mathrm{P} \leq 3\})
$$

Because the lower bound of flood risk level 3 exceeds the required value of water accumulating volume:

$$
\operatorname{Bel}(\{\mathrm{P} \leq 3\})>\mathrm{r}
$$

Compared with the urban flood happened in June 18,2011 , the urban flood risk we got is the same with the factual risk, which shows the availability of random sets and integration operator in urban flood risk based multi-source information fusion.

We also carried out an experiment to compare with our method. According to Zhang et $\mathrm{al}^{43}$, if we consider only one fact of land use resulted from rapid urbanization, the assessment of flood risk is 4 level, which is not factual compared with the recent urban flood happened in June 18 in 2011. These results prove that our method is more available than single factor flood risk assessment method.

Table 7. Cumulative belief and plausibility functions of $E=$

$$
\left\{P \leq P_{0}\right\} \text {. }
$$

\begin{tabular}{lll}
\hline Flood risk level & Bel & Pl \\
\hline 1 & 0 & $34 \%$ \\
2 & $19 \%$ & $66 \%$ \\
3 & $54 \%$ & $89 \%$ \\
4 & 1 & 1 \\
\hline
\end{tabular}

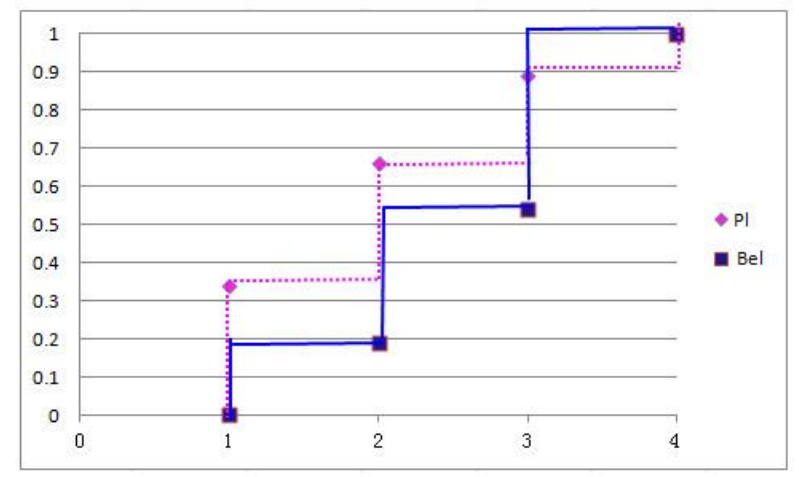

Figure 7.Cumulative belief and plausibility values of urban flood risk measured by a random set $\left(E=\left\{P \leq P_{0}\right\}\right)$.

\subsection{Discussion}

According to the results of Wuhan city urban flood risk assessment and the characteristic of flood risk, we give some management and mitigation measures of the urban flood risk to the local government or emergency planning sectors.

- The management of city should keep pace with the development of city. Exploit first protection later will cause the potential damage in the future.

- Although it is not practical to concede land to lake, we can protect the present lakes. Local government can try to prevent real estate developer to fill the only present lakes, meanwhile, strengthen the management of lakes to make the lake hold the rain better.

- Emergency measures should be activated before the flood risk level to ensure the most quickly response and the minimized loss, which will contribute to the better management of Wuhan city.

Although the area considered in this paper is only one city in China, there are many other areas bearing the flood risk, we will consider the flood prone area and get the flood risk map in China by fusing more multi-source information, which provide potential scientific support for flood risk early warning and management sector and help the local government take actions to reduce vulnerability to urban flood risk and minimize urban flood damage. This will be investigated in future work.

\section{Conclusion}

Flood is a major challenge in both advanced and developing countries, which is a complex process because it is a synthetically function of hazardformative environments, hazard-formative factors and 
hazard-affected bodies. It is difficult to wholly and correctly assess urban flood risk by considering only one factor. Moreover, uncertainty of the flood risk makes it difficult to generate precise estimates of the probability of occurrence. It has been recognized that traditional probability theory may not capture the full scope of uncertainty. However, Random set theory offers an alternative to traditional probability theory to overcome these shortcomings. The significant innovation of the proposed framework is that it allows for the allocation of a probability distribution function to sets based on multi-source sensor information to dealing with the uncertainty.

The results of urban flood risk assessment based on proposed methodology have been compared with the factual flood risk, which show the availability and efficiency of random set theory. The approach proposed in this paper offers an alternative way of analysis when multi-source information must be considered and uncertainty information is unavailable for treating the problem by classical probabilistic methods. The results can provide decision support to draw up flood mitigation measures as a part of the decision support system for flood control authority. Although the example presented is Wuhan city, the implication and recommendation presented have global applications.

\section{Acknowledgements}

The authors thank the anonymous reviewers for their constructive comments and suggestions in improving the quality of this manuscript. The authors are grateful to the support of National Natural Science Foundation of China (No. 40971208), Natural Science Foundation of China (60903197) and National Key Basic Research Program of China (2007CB714107). In addition, the authors are indebted to the experts from Wuhan Water Authority for the data and their generous help.

\section{Reference}

1. F. Melgani, S. B. Serpico and G. Vernazza, Fusion of multitemporal contextual information by neural networks for multisensor image classification, in Proc. 2001 Int. Conf. Geoscience and Remote Sensing (Sydney, NSW, Australia,2001), pp. 2952-2954.

2. I. Corona, G. Giacinto, C. Mazzariello, F. Roli and C. Sansone, Information fusion for computer security: State of the art and open issues, Information Fusion 10 (4) (2009) 274-284

3. C. Stiller, L. F. Puente and M. Kruse, Information fusion for automotive applications - An overview, Information Fusion 12 (4) (2011) 244-252.
4. H. Guo, Z. Xia, L. Chen and X. Pang, Estimation of reliability with hybrid uncertainties in the unified framework of random set theory, in Proc. 2nd Int. Conf. Intelligent Computation Technology and Automation, (Changsha, China, 2009), pp. 507-512.

5. O. Y. Vorob'ov, Random set models of fire spread, Fire Technology 32 (1996) 137-173.

6. H. E. Robbins, On the measure of random set, $I \& I I$. Annals of Mathematical Statistics, 15 (1944) 70-74; 16 (1945) 342-347.

7. E. E. Smith and D. L. Medin, Categories and concepts (Harvard University Press: Cambridge, England, 1981), pp.61-101.

8. E. E. Smith, D. N. Orsherson, Conceptual combination with prototype concepts, Cognitive Science 8 (1984) 337 361.

9. R. A. Tapia, J. R. Tompson, Nonparametric Probability Density Estimation (Johns Hoptkins University Press: Baltimore, USA, 1978).

10. D. F. Votaw, The probability distribution of the measure of a random linear set, Annals of Mathematical Statistics 17 (1946) 240-244.

11. I. R. Goodman, Application of frechet and other randomset averaging techniques to fusion of information, in Proc Int. Conf. International Society for Optical Engineering, (Orlando, FL, USA, 1998), pp. 108-118.

12. S. Mori, Multi-target tracking theory in random set formalism, in Proc. Int. Conf Multisource-Multisensor Information Fusion, (Las Vegas, NV, USA, 1998), pp.116-23.

13. E. J. Trebya, M. J. Clark and S. J. Priest, Confronting flood risk: Implications for insurance and risk transfer, $J$. Environ. Manage 81(4) (2006) 351-359.

14. K. Okubo, M. S. A. Khan and M. Q. Hassan, Hydrological processes of adsorption, sedimentation, and infiltration into the lake bed during the 2004 urban flood in Dhaka city, Bangladesh, Environmental Earth Sciences 60(1) (2010) 95-106.

15. X. Wang, Y. Hao and Y. Lu, Security evaluation on urban flood control system: model construction and application, Journal of Information and Computational Scien. 7(2010) 3193-3200.

16. J. Yan, Z. Fang and Y. Zhou, Study on Scheme Optimization of Urban Flood Disaster Prevention and Reduction, in Proc. Int. Conf. Intelligent and Advanced Systems, (Kuala Lumpur, Malaysia, 2007), pp. 971-976.

17. B. Stalenberg and J. K. Vrijling, Urban flood protection chart, in Proc. Int. Conf. Urban Water, (Heverlee, Belgium, 2008), pp. 257-263.

18. J. A. E. Ten Veldhuis and F. Clemens, Flood risk modeling based on tangible and intangible urban flood damage quantification, Water Sci. Technol. 62(1) (2010) 189-195.

19. W. J. Graham and C. A. Brown, Flood warning systems as a means for reducing urban flood losses, in Proc. 18th Int. Conf. Specialty, (Newark, DE, USA, 1989), pp.281285. 
20. K. U. Kim, H.S. Hwang and C.S. Kim, A prototype of the urban flood warning system using sewer networks connected with SWMM, International Journal of Computer \& Information Science. (2007) 474-483.

21. G. J. P. Schumann, J. C. Neal, D. C. Mason and P. D. Bates, The accuracy of sequential aerial photography and SAR data for observing urban flood dynamics, a case study of the UK summer 2007 floods, Remote Sens. Environ. 115(10) (2011) 2536-2546.

22. C. Wang, T. R. Wan and I. J. Palmer, Urban flood risk analysis for determining optimal flood protection levels based on digital terrain model and flood spreading model, Visual Computer 26(11) (2010) 1369-1381.

23. I. Couso, L. Sanchez and P. Gil, Imprecise distribution function associated to a random set, Information Science 159(1-2) (2004) 109-123.

24. G. Matheron, Random Sets and Integral Geometry (John Wiley \&Sons, New York, 1975).

25. I. S. Molchanov, Theory of Random Sets (Springer-Verlag, Berlin, 2005).

26. H. T. Nguyen, An Introduction to Random Sets (Chapman \& Hall/CRC, Boca Raton, 2006).

27. S. Zhang, G. Lv, H. Gong and H. Zhang. Drainage in Equipment Facilities GIS, (Science Press, Beijing, 2006), pp. 248-252.

28. H.T. Nguyen, Fuzzy and random sets, Fuzzy Sets Syst. 156(3) (2005) 349-356.

29. K. Zhang and Gopal Achari, Uncertainty propagation in environmental decision making using random sets, Procedia Environ. Sci. 2 (2010) 576-584.

30. D. Dubois and H. Prade, Consonant approximation of belief functions, Int. J. Approximate Reasoning. 4(5-6) (1990) 419-449.

31. D. Dubois and H. Prade, Random sets and fuzzy interval analysis, Fuzzy Sets Syst. 42(1) (1991) 87-101.

32. G. J. Klir, Principles of uncertainty: What are they? Why do we need them? Fuzzy Sets Syst. 74(1) (1995) 15-31.

33. G. J. Klir and B. Yuan, Fuzzy Sets and Fuzzy Logic, (Prentice Hall, Englewood Cliffs, 1995).

34. F. Tonon, A. Bernardini and I. Elishakoff, Concept of random sets as applied to the design of structures and analysis of expert opinions for aircraft crash, Chaos Solitons \& Fractals 10(11) (1999) 1855-1868.

35. A. P. Dempster, Upper and lower probabilities induced by a multi-valued mapping, Ann. Math. Statist. 38 (1967), pp. $325-339$

36. G. Shafer, A mathematical theory of evidence. (Princeton University Press, Princeton, 1976).

37. S. Han, Y. Xie, D. Li, P. Li and M. Sun, Risk Analysis and Management of Urban Rainstorm Urban flood In Tianjin, Journal of Hydrodynamics 18 (2006) 552-558.

38. J. Qiu, N. Li, X. Cheng and X. Xia, The simulation system for heavy precipitation in Tianjin City, Journal of Hydraulic Engineering 11 (2000) 34-42 (In Chinese).

39. D. Li, H. Zhang, B. Li and Y. Xie, Basic theory and mathematical modeling of urban rainstorm water logging, J. Hydrodyn. Ser. B. 16 (2004) 17-27.
40. Q. Song and W. Ma, The Analysis of characteristic of Wuhan Rainstorm, Hubei meteorology 3 (1997) 11-13 (In Chinese).

41. L. Ma, H. Zhou, Y. Sun and S. Zhang, Forecast of Urban Water logging Degree in Yinchuan, Urban Roads Bridges \& Flood Control 4 (2009) 59-62 (In Chinese).

42. P. Zhang, L. Wang and N. Zhang, Study on the Early Warning System for Rainstorm Water logging in Wuhan City and its Simulated Results, Torrential Rain and Disasters 29 (2010) 71-75.

43. H. Zhang, W. Ma and X. Wang, Rapid Urbanization and Implications for Flood Risk Management in Hinterland of the Pearl River Delta, China: The Foshan Study, Sensors 8 (2008) 2223-2239. 